\title{
Prioritization of public services for digitalization using fuzzy Z-AHP and fuzzy Z-WASPAS
}

\author{
Duygu Sergi ${ }^{1}[$ ] Irem Ucal Sari²
}

Received: 24 July 2020 / Accepted: 23 November 2020 / Published online: 3 January 2021

(c) The Author(s) 2021

\begin{abstract}
In this paper, public services are analyzed for implementations of Industry 4.0 tools to satisfy citizen expectations. To be able to prioritize public services for digitalization, fuzzy Z-AHP and fuzzy Z-WASPAS are used in the analysis. The decision criteria are determined as reduced cost, fast response, ease of accessibility, reduced service times, increase in the available information and increased quality. After obtaining criteria weights using fuzzy Z-AHP, health care services, waste disposal department, public transportation, information services, social care services, and citizen complaints resolution centers are compared using fuzzy Z-WASPAS that is proposed for the first time in this paper. Results show that health care services have dominant importance for the digitalization among public services.
\end{abstract}

Keywords Digitalization · Fuzzy Z-AHP · Fuzzy Z-WASPAS · Public services

\section{Introduction}

With the spread of digital transformation and digitalization concepts, the integration of physical and digital systems, the creation of smart products and services, and the creation of innovative business models became inevitable. Digitalization requires large-scale and comprehensive transformations in multiple dimensions such as business model, operations, culture and the entire value of the system by providing improvements in various aspects of the business, such as personalization, efficiency and security [1]. When this transformation that provides unique opportunities for value creation and capture, succeed, citizens and businesses will benefit from better access, while governments can reshape the global economy by achieving substantial savings [2].

With this new era, the transition from physical assets to digital assets in the value chain of industries has begun to manifest itself in all industries through many digital

Irem Ucal Sari

ucal@itu.edu.tr

Duygu Sergi

sergid@mef.edu.tr

1 Department of Industrial Engineering, MEF University, Istanbul, Turkey

2 Department of Industrial Engineering, Istanbul Technical University, Istanbul, Turkey transformation applications that contribute in more profitable revenue, sustained competitive advantage, and higher performance [3]. Furthermore, its future impact will have greater importance and opportunities than ever before. Many governments are becoming increasingly aware of the benefits of digitizing their services to better serve citizens and improve the efficiency of the public sector. Concepts such as workforce and process efficiency and effectiveness that provide better management in the provision of public services are being increased with digitalization [4].

Technology is a factor that affects all institutions in terms of service delivery and even changes the institutions structurally and managerially. At this point, information centers, which provide information-based services, are also making efforts to make their services suitable for users who are integrated with technology and integrate their expectations with these tools. Information technologies, one of the important development areas of recent years, have created an information boom that will multiply the existing knowledge. With this explosion of information, information networks and services are become prominent, linking everyone and offering new opportunities for productivity, learning and entertainment [5]. The information produced is managed by information control tools and transmitted to the masses through Internet technology. With the aim of bringing information technologies and industries together, Industry 4.0 concept aims to build smart ecosystems that are integrated with all 
kinds of tools and equipment, equipped with sensors and operators, where all devices can exchange information and data with each other [6].

The main objective of digital transformation is to enhance and refine operational processes and reduce costs by transforming key business operations affecting products and processes [7]. One of the public services in which these transformation practices have gained importance and witnessed major changes in the health care sector. Along with the new digital age, health and care policy shifts from a conventional medical model to a co-managed and integrated approach to optimizing healthcare delivery and that brings lots of innovation [8].

In today's time, social care services are another area in which Industry 4.0 applications, which have become more and more pervasive with the increase in technological advancements in recent years, make life easier for people especially who are old aged and have disabilities [9]. As the health and social care sector continues to automate and grow, it is essential to train that staff in this field in the use of new technologies and are open to changes in the workflow [10].

The digital era is also transforming the public transport sector, which is one of the essential parts of the globalizing world economy. Digitalization in public transport offers new services to increase efficiency and quality, reduce costs, open new revenue streams, and most importantly increase customer experience and loyalty [11]. In addition to changing governance, the adoption of digitalization, which entails challenges such as acquiring new staff profiles or investing in new technologies, forces public transport operators and authorities to redefine their jobs. Besides, governments must keep up with the pace of technological changes and ensure that new technologies can be used and new business models adopted. An important part of the new solutions brought by digitalization includes the exchange of data between the transport vehicles in the public transport infrastructure and the objects in their environment [12].

Digitalization has begun to enter all areas of industrialized life. In recent years, the uncontrolled growth of urban population in developing countries has made waste management an important issue [13]. Also, the waste amount that is produced today is more than ever due to the increasing industrialization, the globalization of trade and the consequent increase of wealth [14]. From this point of view, it can be said that the waste disposal industry is facing great challenges all over the world and that the work is becoming more extensive, complex and expensive. Technology and Industry 4.0 applications play now an important role in waste management. The digitalization and optimization of ongoing services such as waste collection and recycling/disposal are important opportunities for social development and sustainability in terms of both improving human, technical and financial resources and reducing negative environmental impacts [15]. With the digital upswing that causes shell change in waste technologies, many innovations are emerging in this field. Mobile systems, smart sensors, IoT connected technologies and artificial intelligence technologies shelve the waste management problems which are faced by cities to create a healthy environment by eliminating pollution and reducing resource waste [16].

In summary, digitalization in public services is an important and urgent issue to satisfy citizen expectations. As digitalization has become more and more involved in their daily lives, citizens expect to have the convenience of digitalization in public services. Therefore, the digitalization of public services has become a priority for public administrators in order to improve the functionality of the services and to meet the expectations of citizens. Digitalization process and transformation of current processes should be well-managed and coordinated to increase the positive effects and avoid redundant expenses. High costs of the implementation phase are one of the major limitations of digitalization which necessitates managers prioritize the candidate services for digitalization and transform processes one by one. Therefore, the main objective of this study is determined as prioritization of the public services to decide which one should be digitalized earlier to satisfy citizens' expectations. To do this, first public services that could be digitalized are listed, and then the alternative tools, applications are discussed to determine alternative technologies, which will be compared in the study.

Public services that will be compared in the study are selected as health care services, waste disposal department, public transportation, information services, social care services, and citizen complaints resolution centers after the literature review that is given in Sect. 2 digitalization of these services could decrease the idle times and increase efficiency, by this way, service processes could be improved. In this study, available platforms, applications are examined and their main functions are determined for each of the departments.

At the same time, the utilities of the digitalization are examined. Digitalization provides better products by enabling customers with vaster offers, improved use of equipment, lower access costs to customers and more flexibility [17]. Kilpeläinen and Tyrväinen [18] states that the increasing availability of information in digital form allows information to be carried easily. Digitalization aims to exponentially increase the value that companies deliver to customers by offering new functionality, higher reliability, more efficiency and optimization opportunities [19]. On the other hand, through the digitalization, quality and efficiency increase while their costs decrease. Mergel et al. [20] determine expected improvements of the public services with digitalization as increased simplicity, accessibility, quality, 
advantages, efficiency, speed, inclusion, responsiveness, competitiveness, security and transparency. According to Alsaadi et al. [21], the most significant factors for citizens for mobile government services are providing complete services, secure and private information, real-time information, good online customer-service attitudes, reliability, easy navigation, valances services, several interaction channels, tangible services, easy information retrieval and offering context-awareness. Decision criteria for the prioritization of the digitalized public services are determined as reduced cost, fast response, ease of accessibility, reduced service times, increase in the available information and increased quality, combining the criteria gathered from the literature and opinions of the citizens that are involved in the study.

The decision-making methodology proposed in this study combines the analytical hierarchy process (AHP) and WASPAS method using fuzzy Z-numbers. Fuzzy logic is preferred in the analysis to handle uncertain information occurs from unpredictable outcomes of the digitalized services and improvements. A significant difference in fuzzy logic from other logic systems is that it allows the use of verbal variables. In reality, human decisions are ambiguous and not suitable for defining as precise numerical values. Therefore, it would be more realistic to use verbal variables in modelling human decisions. Another feature that distinguishes fuzzy logic from other logic systems is that two features called the law of non-contradiction and the principle of excluded middle, which are very important for other logic systems, and can even be called basic rules, are not valid for fuzzy logic. In fuzzy logic, it cannot be said that a proposition cannot be both true and false at the same time. In the last few years, classical fuzzy sets have been applied in fuzzy decision making and many results have been obtained. However, a problem is that the reliability of the information provided is not sufficiently considered. Compared to the classical fuzzy number, the $\mathrm{Z}$ number is more capable of describing human knowledge since it can describe both restriction and reliability. Information reliability has a considerable impact on the decision-making outcome. Z-numbers consider both uncertainty and reliability of information and therefore it might help the decision-maker manage complex problems.

For the determination of the criteria weights, fuzzy analytical hierarchy process (FAHP) based on Z-numbers is used. The analytic hierarchy process (AHP) method is a useful approach to solve decision-making problems due to its advantages as its ease of application, the ability to analyze benefit and cost criteria simultaneously [22]. Besides being a method that can be easily understood and simplify even complex problems, AHP makes it more understandable by showing weighting with pairwise comparisons easier [23]. In addition, AHP allows the decision-maker to measure the degree of consistency level of its decisions and can perform sensitivity analysis [24]. All these advantages make AHP applicable in more areas than other methods. After determination of weights for these different utilities gained by digitalization, departments and their services are evaluated according to the effects of their digitalization on the utilities using fuzzy Z-WASPAS which is proposed in this study for the first time as a new extension of WASPAS method. WASPAS is a novel method that has been introduced in recent years and has higher consistency and accuracy [25]. The major difference of the fuzzy WASPAS method, which combines WSM and WPS models, from other methods is that it has the advantage of higher accuracy. Also, WASPAS becomes a suitable MCDM method to evaluate alternatives since it overcomes complex multiplication calculations and provides ease of calculations [26]. Therefore, a method that is a combination of AHP and WASPAS methods based on fuzzy Z-numbers is proposed and used in this paper. The outcomes of this study could be used as a road map for the public sector to initialize digital transformation in their services.

The paper is organized as follows. In Sect. 2, a detailed literature review is given on the digitalization of public services and the methodologies used in this paper. Then the applicable Industry 4.0 tools are determined. After introducing the basics of fuzzy Z-AHP, and determination of the proposed fuzzy Z-WASPAS, methods are applied to find the criteria weights and rank the alternatives respectively. Finally, the paper is concluded with the interpretation of the results.

\section{Literature review}

\section{Literature review on digitalization}

Many papers investigate digitalization in public services. Chute and French [9] indicates that considered as a more self-centered application using Industry 4.0 capabilities, "Care 4.0" is a new paradigm that can change the way people develop digital health and care services by focusing on reliable and integrated organizational networks, people and technologies. These networks and tools would provide preventive approaches that form a flexible and sustainable set of integrated health and social care services to enable personalized services that are more responsive to people's needs and desires. Estrela et al. [27] define Health 4.0 as the healthcare extension of Industry 4.0 applications that provide information on the potential for expanding, virtualizing and enabling new health-related processes such as home care, finitude medicine, and personalized/remotely triggered pharmaceutical treatments and transforms them into services. Bisio et al. [28] state that Industry 4.0 and IoT provide substantial support to the healthcare system through the development of remote technologies and the deployment of smart

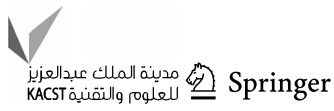


and connected e-health solutions. According to Koop et al. [29] information and communication technology-based, advanced and practical health-related technologies and services, which are implemented in the home environment, have great importance. Bisio et al. [28] define examples of possible smart health applications as cloud-based remote monitoring platforms, wearable sensors for patient rehabilitation, and smart IoT devices for early detection of specific injuries or diseases. They introduced the innovative prototype called "Smart Pants", which consists of multiple sensors, is intended to guide and assist patients remotely during post-stroke rehabilitation therapy and this specially designed prototype uses intelligent sensing. Khalique et al. [30] proposed a new model based on the digitization of the electronic health record for electronic medical data storage describes a layered architecture called the Public Health Framework, which combines different data formats and analysis techniques that may be useful in the public health system. This framework enables the use of electronic health record in a standardized way for public health.

Erkollar and Oberer [31] developed an intelligent transportation system (ITS) using I4.0-related technologies and concepts to improve the quality of transportation by applying analysis, sense, control and communication technologies. ITS offers a wide range of applications that process and share information to improve traffic management, simplify congestion, minimize environmental impacts, and increase the benefits of transportation to commercial users and the public. Davidsson et al. [11] are discussed the opportunities and challenges of the Internet of Things (IoT), which is a wave of advanced digitalization and how public transport and the sustainable development of society can be developed and supported. Great opportunities created by digitalization such as real-time vehicle and delay information, interchange guidance and ticketing support in the public transport sector are discussed and their support to sustainability aspects are presented.

Hong et al. [32] are introduced a model to collect the consumption habits of the city's residents in data pools and rearrange their consumption habits using Smart Waste Systems which are part of the Smart City concept. In this way, the shipment of surplus products is reduced, while especially the negative conditions caused by waste (global warming) are controlled by a sustainable, healthy infrastructure. Besides, analyses by municipalities aim to identify increasing needs due to population growth and prevent wastes in the future. Folianto et al. [33] are designed the system called "Smart bin" to collect and transmit data over a wireless network to determine the fullness of the waste bin. Lozano et al. [34] developed a prototype for the waste monitoring and management platform used in rural environments to obtain measurements of the weight, filling volume and temperature of a waste container. In addition to collecting and analyzing this monitoring data, the platform has a module for optimizing waste collection paths. This module creates ways to save energy, time and ultimately cost from data from dynamically positioned nodes. Wijaya et al. [35] offer a smart waste-bin that can manage waste. The system consists of sensors that measure the waste weight and the fill level of the bin and all incoming data is transmitted to the network environment to manage. Sunny et al. [36] propose an intelligent embedded system called Automated Teller Dustbin (ATD) by developing an efficient convolutional neural network (CNN) based image classifier that detects and recognizes its object to solve the waste management problem that has become a major problem for Bangladesh. This government-supported application promotes the use of an intelligent garbage bin while providing garbage recycling, at the same time contributing to social development with the value of recycling allocated to the object. Yusof et al. [37] present the IoT innovation project, which is a smart waste bin with a real-time monitoring system that combines the solar energy system, sensors and wireless communication technologies. The study aims to provide an efficient and cost-effective waste collection management system that provides a clean, healthy and green environment. According to Anagnostopoulos et al. [38], waste management not only involves the collection of wastes in the field but also the transportation and disposal of them to the appropriate places. Ghose et al. [39] develop appropriate waste storage, collection and disposal plan for India's Asansol Municipality Company. In this study, a GIS optimal routing model that takes minimum cost and distance into consideration in determining efficient collection ways for transporting wastes to the storage area is proposed. Ogdol et al. [40] develop an application by monitoring waste disposal facilities to remove waste using modern IoT technologies. With IoT framework, the situation of the proposed waste disposal sites for filling and collection is analyzed. In this study, which presents a real-time and data-oriented information system, it is possible to easily match waste and facility by considering waste disposal activity per area (weight loss of waste area).

According to Chen et al. [41], next-generation digital libraries which are in the field of information technology apply new concepts such as semantic access, real-time web, cloud computing, mobile web, connected data and context awareness. The study also shows that these libraries using context awareness technology can provide the best possible service for the convenience of users.

Cui et al. [42] indicate that smart nursing homes which are equipped with electronic devices and intelligent systems are of major importance with the rapid growth of the elderly population and the dramatic advancement of health informatics. They proposed a new model, using some tools such as the quality matrix house to constantly identify, allocate and improve the requirements, emphasizes the 
synchronization development of the cyber-physical system with the intelligent maintenance house, and the iterative and lifecycle development processes.

As it is seen from the literature review, nowadays using Industry 4.0 applications in public services is much more popular. Besides that, the papers summarized above are focused on just one aspect of public services. When the mentioned papers are examined in detail, all of the digital features in public services bring significant improvements in citizens' daily lives.

To the best of our knowledge, none of the papers compared the improvements of the individual digital systems in the public sector. To increase the satisfaction of the citizens in public services, it is essential to prioritize digitalized tools in public services to find the best improvement plan that involves digitalization.

\section{Literature review on methodology}

Saaty proposed Analytic Hierarchy Process method in 1980 as a tool for decision making [43]. Since then, it has become one of the most used multi-criteria decision-making methods in the literature. To deal with vagueness in the determination of linguistic statements, many fuzzy extensions of analytic hierarchy process method are proposed which differs in the algorithm and the degree of the fuzziness involved in the analysis. Some of the fuzzy analytic hierarchy process (FAHP) extensions utilize logarithmic least square method [44-46], where some others utilize geometric mean method [47] and fuzzy synthetic extend analysis [48] for FAHP algorithm. FAHP methods also differ from each other with the fuzzy extension that is used in the determination of linguistic statements. In the determination of linguistic scale, triangular fuzzy sets [44, 45, 48], trapezoidal fuzzy sets [47], type-2 fuzzy sets [49, 50], intuitionistic fuzzy sets [51-61], hesitant fuzzy sets [62-64], fuzzy Z-numbers [65-68], Pythagorean fuzzy sets [69] and spherical fuzzy numbers [70] are used.

Zavadskas et al. [71] proposed WASPAS method in 2012 to increase the accuracy of ranking alternatives. Since then, many fuzzy extensions of WASPAS method have been proposed. Intuitionistic fuzzy sets [72-75], triangular fuzzy numbers [76], type-2 fuzzy sets [25, 73, 77, 78], hesitant fuzzy sets [79-81], neutrosophic sets [73, 82], Pythagorean fuzzy sets $[74,83]$, spherical fuzzy sets [84] are used in these fuzzy extensions of WASPAS method.

In the literature, instead of the classic MCDM methods, a hybrid approach which consists of Fuzzy AHP-WASPAS methodologies is also applied using many extensions of the fuzzy sets such as triangular fuzzy numbers [76, 85-87], spherical fuzzy numbers [88-90].

Fuzzy Z-numbers that are introduced by Zadeh in 2011 [91] is a quite new concept that allows overcoming the limitations of ordinary fuzzy numbers in fuzzy set theory. It involves fuzzy reliability in addition to the fuzzy restriction that enables analysts to take into account the uncertainty that occurred from the reliability of the decision-makers. Since it has more capability to describe the uncertainty, there are various approaches which are combined with Z-numbers to evaluate MCDM problems [67, 68, 92-95].

\section{Industry $\mathbf{4 . 0}$ tools for public services}

For this study, public services that are candidates for the digitalization are determined as health care services, waste disposal services, public transportation services, information services, social care services and citizen complaint resolution services, which are the most investigated services from the digitalization aspect in the literature as it is mentioned in the previous section.

\section{Health care services}

The main problems in health care services are crowded clinics, long waiting times for consultations, need to go to the clinic several times for the examinations, getting test results and controlling the results [96]. Industry 4.0 tools can be used in health care services to overcome these problems. An intelligent algorithm will be used to diagnose the given symptoms to assist the doctors. The suggestions of the intelligent algorithm will only be shared with the doctor to prevent wrong diagnosis. To implement Industry 4.0 tools on health care services, first current system should be fully digitalized. The new features in the health care services for the proposed digitalized system will be as follows:

Online consultations especially for the people who are disabled and/or old that could not go to the clinics easily, online consultations could be arranged. Of course, some of the cases need physical consultation but for an initial diagnosis, online consultations could be helpful. This feature decreases the patient load in the clinics.

Online initial diagnosis in emergencies this feature is supposed to be used by emergency health care services. Without this implementation, the initial diagnosis is done with telecommunication. Video calls enable doctors to give instructions to the patient or patient relative in a more appropriate way.

Planning scheduled visits and health consultations actually, most of the planning scheduled visits are done via the internet. This feature makes scheduling open to the public. By this way, patients could see loads of the doctors on time and the patient waiting times decrease.

Ease of access to the information on preventive health care: this feature is especially important for reaching information when the patient does not want to interact with a doctor or sanitarian. It could be helpful for a patient, who wants 
to get rid of drug addiction or who wants to get information on birth control.

Previous data share for agreed citizens in most of the cases, previous treatments and previous diagnosis' of a patient are important to make the diagnosis and choose the best medicine. This feature is optional due to the preferences of the patients but if they agreed, the treatment process will be shorter.

\section{Waste disposal services}

Waste management is another important issue, particularly in larger cities. The main problems in waste disposal services are overloaded bins, unbalanced load in recyclable wastes, wrong waste collection scheduling, poorly organized recyclable waste collection system, illegal waste disposal especially for industrial wastes etc. [97]. By implementation of Industry 4.0 tools on waste disposal services, the new features will be as follows:

Sensors in the bins with the integration of sensors to the domestic solid waste bins, the loaded capacities of the bins can be monitored on time. This enables dynamic scheduling for waste collection vehicles.

Online access to the wastewater analyze results this is important for controlling industrial wastes. In illegal waste disposal to the sewage system, inspectors are warned. Also, this feature could be used by the industries. This leads to cost reduction for industries on controlling of wastes.

Waste measurement this feature is important to reduce waste production. By delimitation for special waste types and effective monitoring, a holistic waste management system can be established. In this system, data for recyclable waste, hazardous waste and industrial waste amounts are collected. The citizens and industries are awarded for the waste reductions in hazardous and industrial waste amounts and raise in the recycled waste amounts.

Tools for special wastes a mobile application is used for scheduling of special waste collection system especially for waste oils, electronic wastes and rubbish. It makes easier the disposal of the special wastes and in this way, urges the citizens to collect special wastes separately.

Online scheduling with the implementation of the proposed system, waste collection vehicles can be monitored on time and if there is a warning from a bin's sensor, waste collection route is changed automatically.

\section{Public transportation services}

Public transportation includes rail systems, marine transportation and bus services. By implementation of IoT technologies, the following information can be given to the citizens:

Additional information about the journey information on forecasted arrival time to the station, forecasted journey time, load rate of the vehicle can be provided by on-time bus (vehicle) tracking.

Alternative route information additionally, alternative routes for public transportation together with the forecasted arrival times can be provided by the integration of the traffic information and the scheduled lines. It is expected to increase the usage of public transportation and decrease traffic pollution with this implementation.

\section{Information services}

Information services are responsible for the announcements and some on-time data declarations for citizens.

Planned power cuts and failures there could be a reminder that notice the planned maintenances for the power system with the information of expected time periods power cuts. Additionally with a link, citizens warn the provider for the failures. This application uses the GPS data and home and work address information of the citizens.

Planned water cuts and failures same as power cut and failures citizens could be warned for water cuts and failures by a reminder. In the application, the expected finishing time for the maintenance will be given timely.

On-time traffic information by this implementation, some additional information about traffic such as closed routes and traffic flow density can be gathered.

Transparent municipalities routine meetings can be broadcast online. Citizens can comment on the issues on time and there could be a person who summarizes the citizen opinions in the meetings. This system enables municipalities being transparent to the citizens.

Planned investments details of the planned investments could be declared to the citizens. By this way, the improvements that citizens need for the proposed investments can be gathered. According to citizens' preferences, planned investments can be prioritized.

\section{Social care services}

Social care services can be categorized into three:

Orphanage and adoption governments are responsible for caring and providing equal opportunities for the orphans. IoT tools could be used for the adoption process to find the best parents for orphans. Online applications, video calls, online documentation could make the process easier. In addition, online monitoring and help can be used for the adaptation period.

Disabled care to provide equal opportunities for disabled citizens, home-based education can be given by IoT tools. Determination of the special needs for disabled citizens, online applications and requests can be used.

Abuses governments are also responsible to protect citizens especially children and women from abuses. IoT 
tools can be used to develop a warning system in case of emergencies.

Besides, for all of the categories, accessible information about the services and detailed reports of the services can be provided online.

\section{Citizen complaints resolution services}

Citizen complaints resolution service is one of the most important communication tools between the citizens and municipalities. The services, which could be digitalized, are detailed as follows:

Online request system online request system enables citizens to determine their complaints easily without long phone calls and enables service providers to act rapidly without lots of documentation.

Online tracking system citizens could reach the workflow and detailed information for their requests easily by online request tracking system.

Interactive request system also, there could be an interactive system for the citizens who want to get information from a responsible person.

\section{Methodology}

Analytic hierarchy process (AHP) is proposed by Saaty [43] in 1980 and since then it has widespread usage in engineering applications. AHP is one of the most used multi-criteria decision-making methods to weight the effects of the criteria and sub-criteria for a determined goal. In the literature, there are many fuzzy extensions of AHP proposed by various authors for different levels of uncertainty. Fuzzy Z-AHP is proposed by Kahraman and Otay [68] in 2018 that is one of the most recent extensions of AHP, which includes fuzzy restriction and fuzzy reliability functions in the comparison phase. Therefore, in this paper, fuzzy Z-AHP is decided to be used to determine criteria weights. In the ranking of alternatives based on the criteria that are analyzed by fuzzy Z-AHP, fuzzy Z-WASPAS method is used. WASPAS method is first proposed by Zavadskas et al. [71] in 2012. It combines the weighted sum model (WSM) and weighted product model (WPM) to increase ranking accuracy. Due to its simplicity and increased accuracy in the ranking of alternatives, it is widely accepted as an efficient decision-making tool [98]. In this paper, the fuzzy Z-WASPAS method is proposed and used to include the uncertainty in the determination of linguistic statements. The framework of the proposed hybrid method is shown in Fig. 1.

\section{Fuzzy Z-numbers}

Z-numbers are introduced by Zadeh [91] in 2011 that is an ordered pair of fuzzy sets; $Z(\tilde{A}, \tilde{B})$. The first component $(\tilde{A})$ of a $Z$-number $Z(\tilde{A}, \tilde{B})$ is a fuzzy restriction of the values of $X$ variable, and the second component $(\tilde{B})$ is referred to as certainty of the fuzzy restriction.

The restriction $R(X): X i s A$ is referred to a possibilistic restriction shown in Eq. (1) where $\mu_{\tilde{A}}(x)$ is the membership function of $\tilde{A}$ :

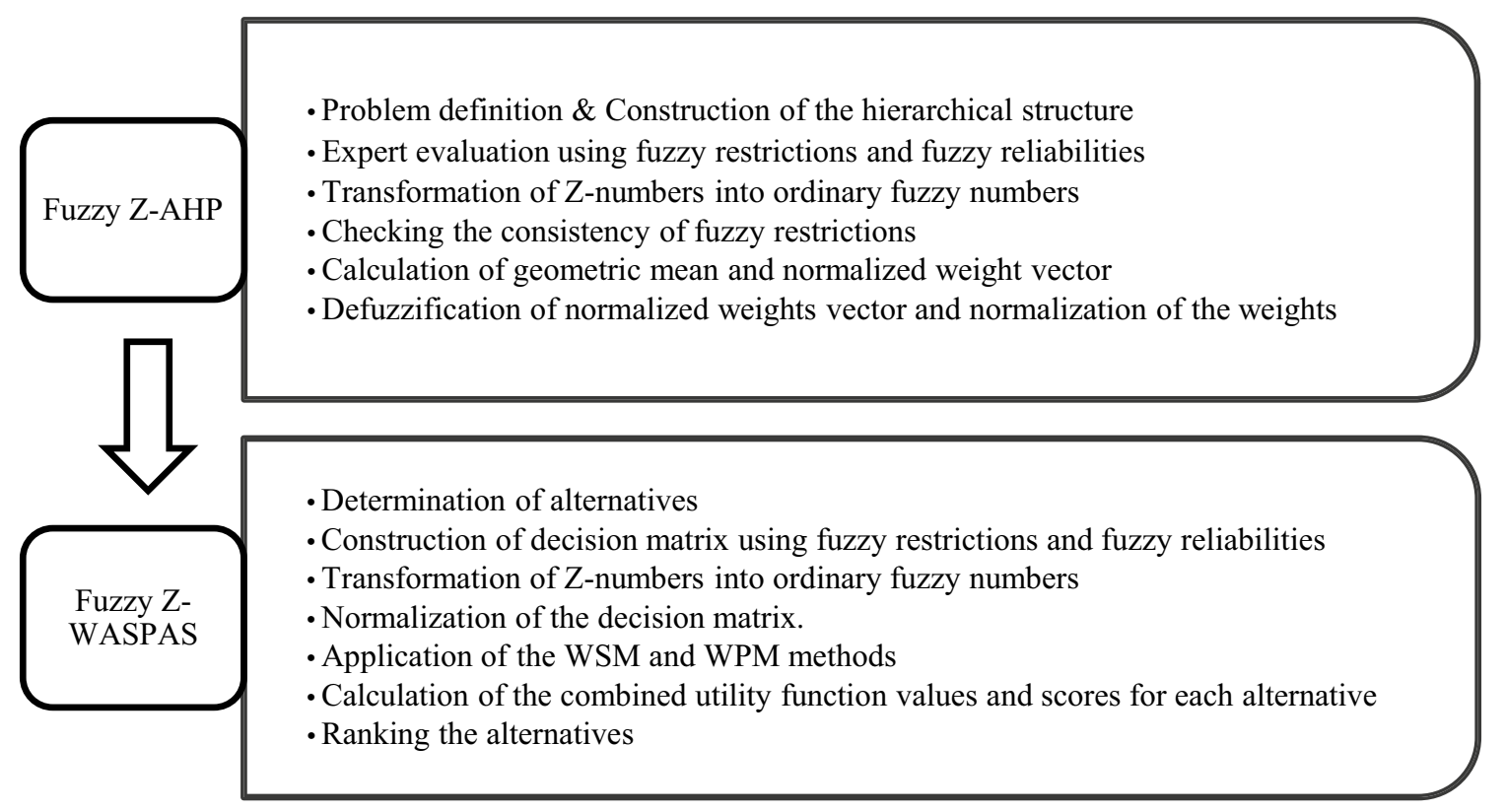

Fig. 1 General framework of the proposed MCDM methodology 
Fig. 2 A simple fuzzy

Z-number

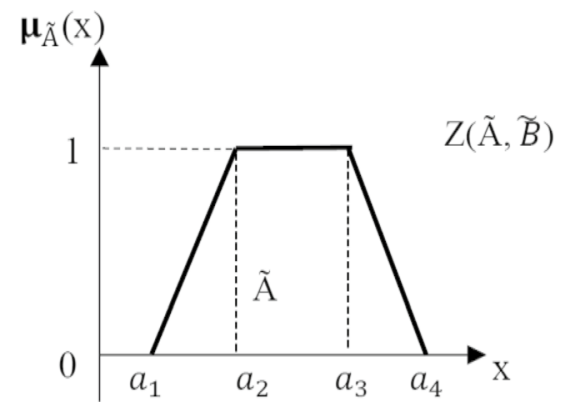

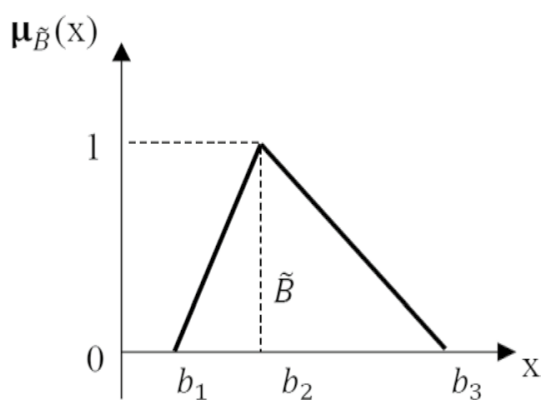

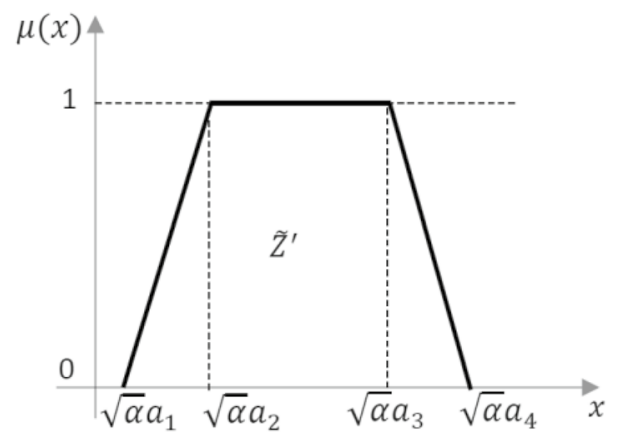

Fig. 3 Ordinary fuzzy number transformed from Z-number

$R(X): X$ is $A \rightarrow \operatorname{Poss}(X=x)=\mu_{\tilde{A}}(x)$.

Figure 2 represents a simple fuzzy Z-number; $Z=(\widetilde{A}, \tilde{B})$ which has a trapezoidal membership function for fuzzy restriction and a triangular membership function for fuzzy reliability.

L e t $\quad \tilde{A}=\left\{x, \mu_{\tilde{A}}(x) \mid \mu(x) \in[0,1]\right\} \quad$ a n d $\tilde{B}=\left\{x, \mu_{\tilde{B}}(x) \mid \mu(x) \in[0,1]\right\}$ where $\mu_{\tilde{A}}(x)$ is a trapezoidal membership function and $\mu_{\tilde{B}}(x)$ is a triangular membership function. To convert a Z-number into a regular fuzzy number, Eqs. 2-4 could be used [94]. First to convert the reliability into a crisp number Eq. 2 can be used:

$\alpha=\frac{b_{1}+2 b_{2}+b_{3}}{4}$.
Then, the weighted Z-number can be denoted as $\tilde{Z}^{\alpha}$ by adding the weight of the reliability to the restriction:

$\tilde{Z}^{\alpha}=\left\{x, \mu_{\tilde{A}^{\alpha}}(x) \mid \mu_{\tilde{A}^{\alpha}}(x)=\alpha \mu_{\tilde{A}}(x), \mu(x) \in[0,1]\right\}$.

The weighted Z-number, in other words weighted restriction, can be converted to an ordinary fuzzy number $\tilde{Z}^{\prime}$ which is shown in Fig. 3 using Eq. 4:

$\tilde{Z}^{\prime}=\left\{x, \mu_{\tilde{Z}^{\prime}}(x) \mid \mu_{\tilde{Z}^{\prime}}(x)=\mu_{\tilde{A}}\left(\frac{x}{\sqrt{\alpha}}\right), \mu(x) \in[0,1]\right\}$.

\section{Fuzzy Z-AHP}

Kahraman and Otay [68] integrated Z-fuzzy numbers with AHP to incorporate vagueness in the evaluations and reliabilities to these evaluations into the AHP. Fuzzy Z-AHP steps are determined as follows [67]:

Step 1. Define the multi-criteria decision making problem and design a hierarchical structure of the problem.

Step 2. Use the scale of linguistic restriction function given in Table 1 and the scale of reliability function presented in Table 2.

Step 3. Construct the pairwise comparison matrices and fill in them with fuzzy Z-numbers using the linguistic terms in Tables 1 and 2.
Table 1 Triangular fuzzy $\mathrm{Z}$ restriction scale for the pairwise comparisons of criteria
Linguistic restriction Triangular fuzzy Z-scale

Equally important (EI)

$(1,1,1 ; 1)$

Weakly more important (WI)

$(1,3,5 ; 1)$

Moderately more important (MI)

$(3,5,7 ; 1)$

Greatly more important (GI)

$(5,7,9 ; 1)$

Absolutely more important (AI)

$(7,9,9 ; 1)$

If factor $i$ has one of the above fuzzy numbers assigned to it when compared with factor $j$, then $j$ has the reciprocal value when compared with $i$
Reciprocals of above 
Table 2 Reliability scale with its corresponding triangular Z-fuzzy numbers

\begin{tabular}{ll}
\hline Linguistic reliability & $\begin{array}{l}\text { Triangular Z-fuzzy } \\
\text { reliability function }\end{array}$ \\
\hline Absolutely reliable (AR) & $(1,1,1 ; 1)$ \\
Strongly reliable (SR) & $(0.7,0.8,0.9 ; 1)$ \\
Very highly reliable (VHR) & $(0.6,0.7,0.8 ; 1)$ \\
Highly reliable (HR) & $(0.5,0.6,0.7 ; 1)$ \\
Fairly reliable (FR) & $(0.4,0.5,0.6 ; 1)$ \\
Weakly reliable (WR) & $(0.3,0.4,0.5 ; 1)$ \\
Very weakly reliable (VWR) & $(0.2,0.3,0.4 ; 1)$ \\
Strongly unreliable (SU) & $(0.1,0.2,0.3 ; 1)$ \\
Absolutely unreliable (AU) & $(0,0.1,0.2 ; 1)$ \\
\hline
\end{tabular}

Step 4. Transform Z-numbers to their corresponding equivalent ordinary fuzzy numbers.

Step 5. Check the consistency of each fuzzy pairwise comparison matrix. Assume $\tilde{A}=\left[\tilde{a}_{i j}\right]$ is a fuzzy positive pairwise comparison matrix and $A=\left[a_{i j}\right]$ is its defuzzified positive pairwise comparison matrix. If the result of the comparisons of $A=\left[a_{i j}\right]$ is consistent, then it can imply that the result of the comparisons of $\tilde{A}=\left[\tilde{a}_{i j}\right]$ is also consistent.

Step 6. Apply Buckley's ordinary fuzzy AHP method [47]. The steps of this method are summarized as follows: Step 6.1 Calculate the geometric mean for each parameter of $\tilde{a}_{i j}$ in the $\mathrm{n}$ dimensional pairwise comparison matrix. Thus, $n \times n$ matrix is converted to $n \times 1$ matrix.

Step 6.2. Sum the values of each parameter in the column in order to normalize the values in $n \times 1$ matrix.

Step 6.3. Apply fuzzy division operation to get the normalized weights vector.

Step 6.4. Defuzzify the normalized weights vector using the center of gravity method given by Eq. 2 .

Step 6.5. Normalize the weights so that their sum is equal to 1.

Step 6.6. Apply Steps (6.1-6.5) for the rest of the pairwise comparison matrices.

Step 6.7. Combine all the weights vectors to determine the best alternative as in classical AHP.

\section{Fuzzy Z-WASPAS}

In the following, the steps of proposed fuzzy Z-WASPAS method are given step by step:

Step 1. Determination of the decision matrix. Use the scale of linguistic restriction function and the scale of reliability function presented in Tables 1 and 2, respectively.

Step 2. Transform Z-numbers to their corresponding equivalent ordinary fuzzy numbers.

Step 3. Normalization of the decision matrix. For the decisions in which the highest score is preferred or in other words for positive criteria Eq. 5 is used for the normalization:

$\widetilde{\bar{x}}_{i j}=\frac{\tilde{x}_{i j}}{\max \tilde{x}_{i j}}$

For the decisions in which the lowest score is preferred or in other words for negative criteria Eq. 6 is used for the normalization:

$\widetilde{\bar{x}}_{i j}=\frac{\min \tilde{x}_{i j}}{\tilde{x}_{i j}}$

Step 4. Apply the methods of weighted sum model and weighted product model.

Step 4.1. Construct weighted normalized decision matrix for weighted sum model (WSM) using Eq. 7 where $\tilde{w}_{j}$ is the fuzzy weight of criterion

$\widetilde{\bar{x}}_{i j W S M}=\widetilde{\bar{x}}_{i j} \tilde{w}_{j}$

Step 4.2. Construct weighted normalized decision matrix for weighted product model (WPM) using Eq. 8:

$\widetilde{\bar{x}}_{i j W P M}=\widetilde{\bar{x}}_{i j}^{\tilde{w}_{j}}$

Step 5. Calculate the combined utility function values of the WASPAS method for each alternative as in Eq. (9):

$U_{i}=\lambda \sum_{j=1}^{n} \widetilde{\bar{x}}_{i j} \tilde{w}_{j}+(1-\lambda) \prod_{j=1}^{n} \widetilde{\bar{x}}_{i j}^{\tilde{w}_{j}}$

where $\lambda$ is determined by the decision maker and belongs to the interval of $[0,1]$.

Step 6. Calculate the score of each alternative by defuzzifying combined utility function values using the center of gravity method given by Eq. 2 .

Step 7. Rank the alternatives starting from the highest value of obtained defuzzified values.

\section{Application}

In this paper, it is aimed to prioritize public services for implementations of Industry 4.0 tools. Decision criteria for the prioritization are determined as reduced cost (RC), fast response (FRs), ease of accessibility (EoA), reduced service 
times (RST), increase in the available information (IAI) and increased quality (IQ). Fuzzy Z-AHP that is detailed in Sect. 4 is used for the prioritization. The steps of the method are applied as follows:

\section{Determination of criteria weights}

Pairwise comparisons are done using the consensus technique with a group of experts. The expert group consists of 8 citizens which use all of the service alternatives for digitalization. The citizens are chosen from different age and income segments to represent a wider population. The pairwise comparison matrix for decision criteria that is obtained from the group interview is shown in Table 3.

Then, construct the pairwise comparison matrix for reliability function using the linguistic terms in Table 4.

The consistency ratio of the pairwise matrix is calculated as 0.091 that means comparisons are consistent. Fuzzy and normalized weights of the criteria are calculated as shown in Table 5 using Buckley's ordinary fuzzy AHP method with the geometric mean.

The process to be performed after this part is to evaluate the alternatives by using the fuzzy Z-WASPAS method, considering the criteria weights obtained.

\section{Prioritization of public services}

A decision matrix is constructed in Table 6 by using step 1 of proposed fuzzy Z-WASPAS.

Then, transform Z-numbers to their corresponding equivalent ordinary fuzzy numbers by using Eq. 4 as shown in Table 7.

In the initial decision matrix, all criteria are benefit criteria therefore the maximum of the alternative scores for each criterion that is desired to be maximum is taken as the reference value. Then, Table 7 is normalized by using Eq. 5 , and normalized decision matrix is obtained as Table 8 .

The weighted normalized decision matrix for weighted sum model are constructed using Eq. 7 and shown in Table 9.
Table 3 Pairwise comparison matrix for restriction of decision criteria
Table 4 Pairwise comparison matrix for reliability of decision criteria

\begin{tabular}{lllllll}
\hline & RC & FR & EoA & RST & IAI & IQ \\
\hline RC & EI & RWI & RMI & RMI & GI & WI \\
FRs & WI & EI & RWI & RWI & GI & MI \\
EoA & MI & WI & EI & WI & AI & MI \\
RST & MI & WI & RWI & EI & GI & MI \\
IAI & RGI & RGI & RAI & RGI & EI & RWI \\
IQ & RWI & RMI & RMI & RMI & WI & EI \\
\hline
\end{tabular}

\begin{tabular}{lllllll}
\hline & RC & FR & EOA & RST & IAI & IQ \\
\hline RC & AR & VWR & FR & FR & VHR & VHR \\
FRs & VHR & AR & VWR & VWR & VHR & FR \\
EOA & FR & VHR & AR & VHR & SR & FR \\
RST & FR & VHR & VWR & AR & VHR & FR \\
IAI & VWR & VWR & SU & VWR & AR & VWR \\
IQ & VWR & FR & FR & FR & VHR & AR \\
\hline
\end{tabular}

Table 5 Fuzzy and defuzzified normalized weights of decision criteria

\begin{tabular}{lll}
\hline & Normalized fuzzy weights & $\begin{array}{l}\text { Normalized } \\
\text { defuzzified } \\
\text { weights }\end{array}$ \\
\hline Reduced cost & $(0.039,0.089,0.242)$ & 0.094 \\
Fast response & $(0.065,0.159,0.461)$ & 0.172 \\
Ease of accessibility & $(0.160,0.426,0.943)$ & 0.399 \\
Reduced service time & $(0.107,0.260,0.665)$ & 0.264 \\
Increased available information & $(0.010,0.048,0.137)$ & 0.019 \\
Increased quality & $(0.021,0.048,0.137)$ & 0.052 \\
\hline
\end{tabular}


Table 6 Decision matrix with linguistic terms

\begin{tabular}{|c|c|c|c|c|c|c|c|c|c|c|c|c|}
\hline \multirow[t]{3}{*}{ Criterion } & \multicolumn{6}{|c|}{ Restriction scale } & \multicolumn{6}{|c|}{ Reliability scale } \\
\hline & \multicolumn{6}{|c|}{ Alternatives } & \multicolumn{6}{|c|}{ Alternatives } \\
\hline & HCS & WDS & PTS & IS & SCS & CCRS & HCS & WDS & PTS & IS & SCS & CCRS \\
\hline $\mathrm{RC}$ & EI & GI & WI & MI & WI & MI & SR & FR & HR & HR & VHR & SR \\
\hline FR & RGI & EI & RMI & RWI & RMI & RWI & VHR & VHR & HR & VHR & SR & VHR \\
\hline EoA & RWI & MI & EI & MI & MI & MI & SR & HR & VHR & SR & VHR & SR \\
\hline RST & RMI & WI & RMI & EI & RWI & WI & SR & VHR & VHR & HR & VHR & HR \\
\hline IAI & RWI & MI & RMI & WI & EI & WI & VHR & FR & HR & HR & HR & FR \\
\hline IQ & RMI & WI & RMI & RWI & RWI & EI & VHR & HR & VHR & HR & SR & VHR \\
\hline
\end{tabular}

Table 7 Initial decision matrix with fuzzy numbers

\begin{tabular}{lllllll}
\hline Criterion & Alternatives & & & & \\
\cline { 2 - 6 } & HCS & WDS & PTS & IS & SCS & CCRS \\
\hline RC & $(6.26,8.05,8.05)$ & $(0.71,2.12,3.54)$ & $(2.32,3.87,5.42)$ & $(2.32,3.87,5.42)$ & $(4.18,5.86,7.53)$ & $(6.26,8.05,8.05)$ \\
FR & $(4.18,5.86,7.53)$ & $(4.18,5.86,7.53)$ & $(2.32,3.87,5.42)$ & $(4.18,5.86,7.53)$ & $(6.26,8.05,8.05)$ & $(4.18,5.86,7.53)$ \\
EoA & $(6.26,8.05,8.05)$ & $(2.32,3.87,5.42)$ & $(4.18,5.86,7.53)$ & $(6.26,8.05,8.05)$ & $(4.18,5.86,7.53)$ & $(6.26,8.05,8.05)$ \\
RST & $(6.26,8.05,8.05)$ & $(4.18,5.86,7.53)$ & $(4.18,5.86,7.53)$ & $(2.32,3.87,5.42)$ & $(4.18,5.86,7.53)$ & $(2.32,3.87,5.42)$ \\
IAI & $(4.18,5.86,7.53)$ & $(0.71,2.12,3.54)$ & $(2.32,3.87,5.42)$ & $(2.32,3.87,5.42)$ & $(2.32,3.87,5.42)$ & $(0.71,2.12,3.54)$ \\
IQ & $(4.18,5.86,7.53)$ & $(2.32,3.87,5.42)$ & $(4.18,5.86,7.53)$ & $(2.32,3.87,5.42)$ & $(6.26,8.05,8.05)$ & $(4.18,5.86,7.53)$ \\
\hline
\end{tabular}

Table 8 Normalized decision matrix

\begin{tabular}{lllllll}
\hline Criterion & Alternatives & \multicolumn{3}{l}{} & \\
\cline { 2 - 7 } & HCS & WDS & PTS & IS & SCS & CCRS \\
\hline RC & $(0.78,1,1)$ & $(0.09,0.26,0.44)$ & $(0.29,0.48,0.67)$ & $(0.29,0.48,0.67)$ & $(0.52,0.73,0.94)$ & $(0.78,1,1)$ \\
FR & $(0.52,0.73,0.94)$ & $(0.52,0.73,0.94)$ & $(0.29,0.48,0.67)$ & $(0.52,0.73,0.94)$ & $(0.78,1,1)$ & $(0.52,0.73,0.94)$ \\
EoA & $(0.78,1,1)$ & $(0.29,0.48,0.67)$ & $(0.52,0.73,0.94)$ & $(0.78,1,1)$ & $(0.52,0.73,0.94)$ & $(0.78,1,1)$ \\
RST & $(0.78,1,1)$ & $(0.52,0.73,0.94)$ & $(0.52,0.73,0.94)$ & $(0.29,0.48,0.67)$ & $(0.52,0.73,0.94)$ & $(0.29,0.48,0.67)$ \\
IAI & $(0.56,0.78,1)$ & $(0.09,0.28,0.47)$ & $(0.31,0.51,0.72)$ & $(0.31,0.51,0.72)$ & $(0.31,0.51,0.72)$ & $(0.09,0.28,0.47)$ \\
IQ & $(0.52,0.73,0.94)$ & $(0.29,0.48,0.67)$ & $(0.52,0.73,0.94)$ & $(0.29,0.48,0.67)$ & $(0.78,1,1)$ & $(0.52,0.73,0.94)$ \\
\hline
\end{tabular}

Table 9 Weighted normalized decision matrix for weighted sum model

\begin{tabular}{|c|c|c|c|c|c|c|}
\hline \multirow[t]{2}{*}{ Criterion } & \multicolumn{6}{|l|}{ Alternatives } \\
\hline & HCS & WDS & PTS & IS & SCS & CCRS \\
\hline $\mathrm{RC}$ & $\begin{array}{l}(0.073,0.094 \\
0.094)\end{array}$ & $\begin{array}{l}(0.008,0.025 \\
0.041)\end{array}$ & $\begin{array}{l}(0.027,0.045 \\
0.063)\end{array}$ & $\begin{array}{l}(0.027,0.045 \\
0.063)\end{array}$ & $\begin{array}{l}(0.049,0.068 \\
0.088)\end{array}$ & $(0.073,0.094,0.094)$ \\
\hline FR & $\begin{array}{l}(0.089,0.125 \\
0.161)\end{array}$ & $\begin{array}{l}(0.089,0.125 \\
0.161)\end{array}$ & $\begin{array}{l}(0.050,0.083 \\
0.116)\end{array}$ & $\begin{array}{l}(0.089,0.125 \\
0.161)\end{array}$ & $\begin{array}{l}(0.134,0.172 \\
0.172)\end{array}$ & $(0.089,0.125,0.161)$ \\
\hline EoA & $\begin{array}{l}(0.311,0.399 \\
0.399)\end{array}$ & $\begin{array}{l}(0.115,0.192 \\
0.269)\end{array}$ & $\begin{array}{l}(0.207,0.291 \\
0.374)\end{array}$ & $\begin{array}{l}(0.311,0.399 \\
0.399)\end{array}$ & $\begin{array}{l}(0.207,0.291 \\
0.374)\end{array}$ & $(0.311,0.399,0.399)$ \\
\hline RST & $\begin{array}{l}(0.205,0.264 \\
0.264)\end{array}$ & $\begin{array}{l}(0.137,0.192 \\
0.247)\end{array}$ & $\begin{array}{l}(0.137,0.192 \\
0.247)\end{array}$ & $\begin{array}{l}(0.076,0.127 \\
0.178)\end{array}$ & $\begin{array}{l}(0.137,0.192 \\
0.247)\end{array}$ & $(0.076,0.127,0.178)$ \\
\hline IAI & $\begin{array}{l}(0.011,0.015 \\
0.019)\end{array}$ & $\begin{array}{l}(0.002,0.005 \\
0.009)\end{array}$ & $\begin{array}{l}(0.006,0.010 \\
0.014)\end{array}$ & $\begin{array}{l}(0.006,0.010 \\
0.014)\end{array}$ & $\begin{array}{l}(0.006,0.010 \\
0.014)\end{array}$ & $(0.002,0.005,0.009)$ \\
\hline IQ & $\begin{array}{c}(0.027,0.038 \\
0.048)\end{array}$ & $\begin{array}{c}(0.015,0.025 \\
0.035)\end{array}$ & $\begin{array}{c}(0.027,0.038 \\
0.048)\end{array}$ & $\begin{array}{c}(0.015,0.025 \\
0.035)\end{array}$ & $\begin{array}{c}(0.040,0.052 \\
0.052)\end{array}$ & $(0.027,0.038,0.048)$ \\
\hline
\end{tabular}


Table 10 Weighted normalized decision matrix for weighted product model

\begin{tabular}{|c|c|c|c|c|c|c|}
\hline \multirow[t]{2}{*}{ Criterion } & \multicolumn{6}{|l|}{ Alternatives } \\
\hline & HCS & WDS & PTS & IS & SCS & CCRS \\
\hline $\mathrm{RC}$ & $(0.977,1,1)$ & $\begin{array}{l}(0.797,0.883 \\
0.926)\end{array}$ & $\begin{array}{l}(0.890,0.934 \\
0.964)\end{array}$ & $\begin{array}{c}(0.890,0.934 \\
0.964)\end{array}$ & $\begin{array}{c}(0.940,0.971 \\
0.994)\end{array}$ & $(0.977,1,1)$ \\
\hline FR & $\begin{array}{l}(0.893,0.947 \\
0.989)\end{array}$ & $\begin{array}{l}(0.893,0.947 \\
0.989)\end{array}$ & $\begin{array}{l}(0.807,0.881 \\
0.934)\end{array}$ & $\begin{array}{c}(0.893,0.947, \\
0.989)\end{array}$ & $(0.958,1,1)$ & $(0.893,0.947,0.989)$ \\
\hline EoA & $(0.904,1,1)$ & $\begin{array}{l}(0.608,0.746 \\
0.854)\end{array}$ & $(0.770,0.81,0.974)$ & $(0.904,1,1)$ & $\begin{array}{l}(0.770,0.881 \\
0.974)\end{array}$ & $(0.904,1,1)$ \\
\hline RST & $(0.936,1,1)$ & $\begin{array}{l}(0.841,0.920 \\
0.983)\end{array}$ & $\begin{array}{l}(0.841,0.920 \\
0.983)\end{array}$ & $\begin{array}{l}(0.720,0.824 \\
0.901)\end{array}$ & $\begin{array}{c}(0.841,0.920 \\
0.983)\end{array}$ & $(0.720,0.824,0.901)$ \\
\hline IAI & $(0.989,0.995,1.00)$ & $\begin{array}{l}(0.956,0.976 \\
0.986)\end{array}$ & $\begin{array}{l}(0.978,0.987 \\
0.994)\end{array}$ & $\begin{array}{l}(0.978,0.987, \\
0.994)\end{array}$ & $\begin{array}{l}(0.978,0.987, \\
0.994)\end{array}$ & $(0.956,0.976,0.986)$ \\
\hline IQ & $\begin{array}{c}(0.967,0.984 \\
0.997)\end{array}$ & $\begin{array}{c}(0.938,0.963 \\
0.980)\end{array}$ & $\begin{array}{c}(0.967,0.984 \\
0.997)\end{array}$ & $\begin{array}{c}(0.938,0.963, \\
0.980)\end{array}$ & $(0.987,1,1)$ & $(0.967,0.984,0.997)$ \\
\hline
\end{tabular}

Table 11 Importance based on the WSM and WPM and combined utility function values

\begin{tabular}{llll}
\hline & WSM & WPM & $\mathrm{U}_{\mathrm{i}}$ \\
\hline RC & $(0.358,0.467,0.493)$ & $(0.353,0.463,0.493)$ & $(0.711,0.931$, \\
& & & $0.985)$ \\
FR & $(0.183,0.282,0.381)$ & $(0.163,0.270,0.371)$ & $(0.347,0.552$, \\
& & & $0.752)$ \\
EoA & $(0.227,0.329,0.431)$ & $(0.220,0.324,0.426)$ & $(0.447,0.653$, \\
& & & $0.857)$ \\
RST & $(0.262,0.366,0.425)$ & $(0.237,0.346,0.418)$ & $(0.499,0.712$, \\
& & & $0.843)$ \\
IAI & $(0.287,0.392,0.473)$ & $(0.281,0.388,0.472)$ & $(0.568,0.781$, \\
& & & $0.945)$ \\
IQ & $(0.289,0.394,0.445)$ & $(0.262,0.375,0.437)$ & $(0.551,0.769$, \\
& & & $0.882)$ \\
\hline
\end{tabular}

For weighted product model, weighted normalized decision matrix shown in Table 10 are constructed using Eq. 8.

For each alternative, importance based on the WSM and WPM, combined utility function values are calculated by using Eq. 9 as shown in Table 11, where $\lambda$ is determined as 0.5 by the decision-maker.

Then, the score of each alternative is determined by defuzzifying combined utility function values using the center of gravity method by Eq. 2 . The alternatives starting from the highest value of obtained defuzzified values are ranked and the final ranking of the alternatives is given in Table 12.

According to the result achieved in Table 12, the health care services department is determined as the first department for the application of Industry 4.0 tools. Due to the difference between the first two alternatives is relatively small, it is also planned to start digitalization activities for the social care services department.
Table 12 Ranking of the alternatives

\begin{tabular}{lll}
\hline & Score values & Ranking \\
\hline HCS & 0.2185 & 1 \\
WDS & 0.1394 & 6 \\
PTS & 0.1641 & 5 \\
IS & 0.1721 & 4 \\
SCS & 0.1914 & 2 \\
CCRS & 0.1842 & 3 \\
\hline
\end{tabular}

To find the sensitivity of the results according to determined $\lambda$ values, the calculations of utility functions, score functions and rankings are done for lower and upper limits that are and $\lambda=0$ and $\lambda=1$. Although utility functions vary in a close range, this difference has no effect on rankings. The results are given in Table 13.

\section{Comparison of the proposed methods with their ordinary fuzzy equivalents}

To compare the results of the proposed method with existing methods, ordinary fuzzy AHP and ordinary fuzzy WASPAS methods. Reliability comparisons of the decision-makers determine the reliabilities of the statements given in the restriction comparison matrix. Since the ordinary fuzzy methods assume that the decision-makers are reliable, reliability comparisons could not be applicable in the evaluations. Therefore, just the restriction comparisons of the decision-makers are used in the ordinary fuzzy AHP and fuzzy WASPAS methods using the scale given in Table 1.

As it can be seen from Table 14, the criteria weights are calculated slightly different using fuzzy Z-AHP than crisp AHP, but the ranking of the criteria weights remain same 
Table 13 Sensitivity calculations based on $\lambda$ values

\begin{tabular}{|c|c|c|c|c|c|c|}
\hline & \multicolumn{3}{|l|}{$\lambda=0$} & \multicolumn{3}{|l|}{$\lambda=1$} \\
\hline & $\mathrm{U}_{\mathrm{i}}$ & Score values & Ranking & $\mathrm{U}_{\mathrm{i}}$ & Score values & Ranking \\
\hline $\mathrm{HCS}$ & $(0.706,0.927,0.985)$ & 0.2219 & 1 & $(0.716,0.935,0.986)$ & 0.2153 & 1 \\
\hline WDS & $(0.327,0.539,0.742)$ & 0.1389 & 6 & $(0.367,0.564,0.762)$ & 0.1399 & 6 \\
\hline PTS & $(0.440,0.648,0.853)$ & 0.1660 & 5 & $(0.454,0.658,0.862)$ & 0.1623 & 5 \\
\hline IS & $(0.475,0.693,0.836)$ & 0.1715 & 4 & $(0.524,0.731,0.850)$ & 0.1729 & 4 \\
\hline SCS & $(0.563,0.776,0.945)$ & 0.1943 & 2 & $(0.573,0.785,0.946)$ & 0.1887 & 2 \\
\hline CCRS & $(0.525,0.749,0.875)$ & 0.1836 & 3 & $(0.578,0.788,0.889)$ & 0.1849 & 3 \\
\hline
\end{tabular}

Table 14 Comparison of fuzzy AHP and fuzzy Z-AHP results

\begin{tabular}{lll}
\hline & $\begin{array}{l}\text { Defuzzified weights calculated by } \\
\text { Fuzzy AHP }\end{array}$ & $\begin{array}{l}\text { Defuzzified weights cal- } \\
\text { culated by Fuzzy Z-AHP }\end{array}$ \\
\hline Reduced cost & 0.095 & 0.094 \\
Fast response & 0.183 & 0.172 \\
Ease of accessibility & 0.375 & 0.399 \\
Reduced service time & 0.269 & 0.264 \\
Increased available information & 0.025 & 0.019 \\
Increased quality & 0.054 & 0.052 \\
\hline
\end{tabular}

Table 15 Rankings of the alternatives using fuzzy WASPAS and fuzzy Z-WASPAS

\begin{tabular}{llllll}
\hline & \multicolumn{2}{l}{ Fuzzy WASPAS } & & \multicolumn{2}{l}{ Fuzzy Z-WASPAS } \\
\cline { 2 - 3 } \cline { 5 - 6 } \cline { 5 - 6 } & Score values & Ranking & & Score values & Ranking \\
\hline HCS & 0.2098 & 1 & 0.2185 & 1 \\
WDS & 0.1486 & 6 & & 0.1394 & 6 \\
PTS & 0.1688 & 5 & 0.1641 & 5 \\
IS & 0.1728 & 4 & & 0.1721 & 4 \\
SCS & 0.1914 & 2 & 0.1914 & 2 \\
CCRS & 0.1821 & 3 & 0.1842 & 3 \\
\hline
\end{tabular}

for this case. Therefore, it can be said that fuzzy Z-AHP is in convenience with the classical AHP. The differences between the weights occur from the information gained by reliability assessments which can be useful in the assessment of alternatives.

When the WASPAS method is applied to linguistic expert judgements using crisp AHP weights, the ranking of the alternatives is found same with the fuzzy Z-WASPAS's. However, as it can be seen from Table 15, the difference between the scores of the first and last alternatives in fuzzy Z-WASPAS increased with the inclusion of more information in the analysis for the evaluation of decision-makers. The results of the comparison indicate that especially when the weights of criteria and alternatives are closer to each other, the differences can be figured out better using Z-number based methods.

\section{Conclusion}

The expectations and the habits of the customers are rapidly changing as they gain more accessibility to technology in their daily lives. This leads to a big transformation on the customer service systems. People are getting used to reaching information easily by the utilization of IoT technologies in service systems. As well as the organizations, the public sector should also focus on digital transformation due to this change in the expectations of the citizens.

In the literature review, it is found that the papers dealing with digitalization on public services are focused on just one aspect of the public services whereas all of the digital features in public services bring significant improvements in citizens' daily lives. Public services could utilize from digitalization to analyze consumption of resources, decrease wastes and increase efficiency on the service time for different activities. Additionally, digitalization will provide a more detailed and larger data on citizens' changing behaviours and their new expectations from the managers. On the other hand, citizens need to have accessibility to the information they need using IoT tools and if it is possible, get the service online. From that driving point, the main objective of this study is determined as prioritization of the public services to decide which one should be digitalized earlier.

In this paper, health care services, waste management department, public transportation, information services, social care services, and citizen complaints resolution 
centers are selected for digitalization alternatives. Decision criteria are determined as reduced cost, fast response, ease of accessibility, reduced service times, increase in the available information and increased quality. The biggest limitation of this study, which is dealt with using fuzzy logic, is the uncertainty in the prospective developments in digital technology and the impacts of digitalization.

Fuzzy Z-AHP is used to determine criteria weights and fuzzy Z-WASPAS is proposed and used to compare the alternatives. AHP and WASPAS are among the most preferred MCDM methods because they provide ease of application. In order to represent uncertain information in the calculations, fuzzy Z-numbers, which provide superiority over other fuzzy extensions since it also includes reliability, are used. The results of the study show that health care services have dominant importance among alternatives. Therefore, health care services are selected as prior services for the digitalization. The results of the study could be used as a road map for public managers to improve their services and satisfy citizen expectations.

For further research, it is suggested to extend the analysis for health care services to determine which tools should be implemented. In addition, economic analysis for different tool combinations could be done.

\section{Compliance with ethical standards}

Conflict of interest On behalf of all authors, the corresponding author states that there is no conflict of interest.

Open Access This article is licensed under a Creative Commons Attribution 4.0 International License, which permits use, sharing, adaptation, distribution and reproduction in any medium or format, as long as you give appropriate credit to the original author(s) and the source, provide a link to the Creative Commons licence, and indicate if changes were made. The images or other third party material in this article are included in the article's Creative Commons licence, unless indicated otherwise in a credit line to the material. If material is not included in the article's Creative Commons licence and your intended use is not permitted by statutory regulation or exceeds the permitted use, you will need to obtain permission directly from the copyright holder. To view a copy of this licence, visit http://creativecommons.org/licenses/by/4.0/.

\section{References}

1. Ismail MH, Khater M, Zaki M (2017) Digital business transformation and strategy: what do we know so far. Camb Serv Alliance 10

2. Eggers WD, Bellman J (2015) The journey to government's digital transformation. Deloitte. See https://www2.deloitte.com/uk/en/ pages/public-sector/articles/the-journey-to-governments-digitaltransformation.html Accessed 7 Feb 2018

3. Schwertner K (2017) Digital transformation of business. Trakia J Sci 15(1):388-393
4. Casalino N, Draoli M, Martino M (2013) Organizing and promoting value services in public sector by a new e-government approach. In: Proceedings of XIV Workshop dei Docenti e Ricercatori di Organizzazione Aziendale (WOA 2013), Università La Sapienza, Rome

5. Barker P (2002) Technologies for information, communication, and access. In: Olson D, DeRuyter F (eds) Clinicians guide to assistive technology. Mosby Inc, St. Louis, pp 3-13

6. Roblek V, Meško M, Krapež A (2016) A complex view of industry 40. Sage Open 6(2):2158244016653987

7. Matt C, Hess T, Benlian A (2015) Digital transformation strategies. Bus Inform Syst Eng 57(5):339-343

8. Coile RC Jr (2000) The digital transformation of health care (Health Care Meets E-Commerce). Physician Exec 26(1):8-15

9. Chute C, French T (2019) Introducing care 4.0: an integrated care paradigm built on industry 4.0 capabilities. Int J Environ Res Public Health 16(12):2247

10. OECD Publishing, \& Organization for Economic Cooperation and Development (OECD) Staff (2019) Health at a glance 2019: OECD Indicators, OECD Publishing, Paris, https://doi. org/https://doi.org/10.1787/4dd50c09-en

11. Davidsson P, Hajinasab B, Holmgren J, Jevinger Å, Persson JA (2016) The fourth wave of digitalization and public transport: opportunities and challenges. Sustainability 8(12):1248

12. Camacho TD, Foth M, Rakotonirainy A (2012) Pervasive technology and public transport: Opportunities beyond telematics. IEEE Pervasive Comput 12(1):18-25

13. Demir G, Ozcan HK, Karakus PK, Bakis Y (2017) Solid waste collection route optimisation by geographical information system in Fatih, Istanbul. Turkey Int J Glob Warm 11(3):263-272

14. ISWA-International solid waste association (2012) Globalization and waste management. Phase 1: concepts and facts

15. Abdel-Shafy HI, Mansour MS (2018) Solid waste issue: sources, composition, disposal, recycling, and valorization. Egypt J Petrol 27(4): 1275-1290

16. Husein $\mathrm{AH}$ (2019) Internet of things (IOT): research challenges and future applications. Int J Adv Comput Sci Appl 10(6):77-82

17. Anderson $C$ (2006) The long tail: why the future of business is selling less of more. Hachette Books, New York

18. Kilpeläinen T, Tyrväinen P (2004) The degree of digitalization of the information overflow. In: Proceedings of the Sixth Conference on Enterprise Information Systems (ICEIS), pp 367-374

19. Porter ME, Heppelmann JE (2014) How smart, connected products are transforming competition. Harvard Bus Rev 92(11):64-88

20. Mergel I, Edelmann N, Haug N (2019) Defining digital transformation: results from expert interviews. Gov Inform Q 36(4):101385

21. Alsaadi MR, Ahmad SZ, Hussain M (2018) A quality function deployment strategy for improving mobile-government service quality in the Gulf cooperation council countries. Benchmarking 25(8):3276-3295

22. Ustali NK, Tosun N Bulanık AHP ve Bulanık WASPAS Yöntemleri ile Yeni Ürün Seçimi. Pazarlama İçörüsü Üzerine Çalışmalar $3(2): 25-34$

23. Göksu A, Güngör İ (2008) Bulanik analitik hiyerarşik proses ve üniversite tercih siralamasinda uygulanmasi. Suleyman Demirel Univ J Fac Econ Adm Sci 13(3):1-26

24. Toksari M, Toksari MD (2011) Bulanik Analitik Hiyerarsi Prosesi (AHP) yaklasimi kullanilarak hedef pazarin belirlenmesi. METU Studies in Development 38(1):51

25. Deveci M, Canıtez F, Gökaşar I (2018) WASPAS and TOPSIS based interval type-2 fuzzy MCDM method for a selection of a car sharing station. Sustain Cities Soc 41:777-791

26. Xiong L, Zhong S, Liu S, Zhang X, Li Y (2020) An approach for resilient-green supplier selection based on WASPAS, BWM, 
and TOPSIS under intuitionistic fuzzy sets. Math Problems Eng 2020:1761893

27. Estrela VV, Monteiro ACB, França RP, Iano Y, Khelassi A, Razmjooy $\mathrm{N}$ (2018) Health 4.0: applications, management, technologies and review. Med Technol J 2(4):262-276

28. Bisio I, Garibotto C, Grattarola A, Lavagetto F, Sciarrone A (2018) Exploiting context-aware capabilities over the internet of things for industry 4.0 applications. IEEE Netw 32(3):101-107

29. Koop CE, Mosher R, Kun L, Geiling J, Grigg E, Long S, Rosen JM (2008) Future delivery of health care: Cybercare. IEEE Eng Med Biol Mag 27(6):29-38

30. Khalique F, Khan SA, Nosheen I (2019) A framework for public health monitoring, analytics and research. IEEE Access 7:101309-101326

31. Erkollar A, Oberer B (2018) Sustainable cities need smart transportation: the Industry 4.0 Transportation Matrix. Sigma J Eng Nat Sci 9(4):359-370

32. Hong I, Park S, Lee B, Lee J, Jeong D, Park S (2014) IoT-based smart garbage system for efficient food waste management. Sci World J 2014:646953

33. Folianto F, Low YS, Yeow WL (2015) Smartbin: smart waste management system. In: 2015 IEEE Tenth International Conference on Intelligent Sensors, Sensor Networks and Information Processing (ISSNIP). IEEE, pp 1-2

34. Lozano A, Caridad J, De Paz JF, Villarrubia Gonzalez G, Bajo J (2018) Smart waste collection system with low consumption LoRaWAN nodes and route optimization. Sensors 18(5):1465

35. Wijaya AS, Zainuddin Z, Niswar M (2017) Design a smart waste bin for smart waste management. In: 2017 5th International Conference on Instrumentation, Control, and Automation (ICA). IEEE, pp 62-66

36. Sunny MSH, Dipta DR, Hossain S, Faruque HMR, Hossain E (2019) Design of a convolutional neural network based smart waste disposal system. In: 2019 1st International Conference on Advances in Science, Engineering and Robotics Technology (ICASERT). IEEE, pp 1-5

37. Yusof NM, Zulkifli MF, Yusof M, Azman A (2018) Smart waste bin with real-time monitoring system. Int J Eng Technol 7(229):725-729

38. Anagnostopoulos T, Zaslavsky A, Kolomvatsos K, Medvedev A, Amirian P, Morley J, Hadjieftymiades S (2017) Challenges and opportunities of waste management in IoT-enabled smart cities: a survey. IEEE Trans Sustain Comput 2(3):275-289

39. Ghose MK, Dikshit AK, Sharma SK (2006) A GIS based transportation model for solid waste disposal-a case study on Asansol municipality. Waste Manag 26(11):1287-1293

40. Ogdol JMG, Samar BLT, Cataroja C (2019) IOT-based framework for a centralized monitoring of solid waste disposal facilities. J High Educ Res Discip 3(2):43-52

41. Chen MY, Lughofer ED, Noh Y (2013) A study on next-generation digital library using context-awareness technology. Lib Hi Tech 31(2):236-253

42. Cui F, Ma L, Hou G, Pang Z, Hou Y, Li L (2020) Development of smart nursing homes using systems engineering methodologies in industry 4.0. Enterp Inform Syst 14(4):463-479

43. Saaty TL (1980) The analytic hierarchy process: planning, priority setting, resource allocation. McGraw-Hill Inc, New York

44. Van Laarhoven PJ, Pedrycz W (1983) A fuzzy extension of Saaty's priority theory. Fuzzy Sets Syst 11(1-3):229-241

45. Boender CGE, De Graan JG, Lootsma FA (1989) Multi-criteria decision analysis with fuzzy pairwise comparisons. Fuzzy Sets Syst 29(2):133-143

46. Wang YM, Elhag TM, Hua Z (2006) A modified fuzzy logarithmic least squares method for fuzzy analytic hierarchy process. Fuzzy Sets Syst 157(23):3055-3071
47. Buckley JJ (1985) Fuzzy hierarchical analysis. Fuzzy Sets Syst 17(3):233-247

48. Chang DY (1996) Applications of the extent analysis method on fuzzy AHP. Eur J Oper Res 95(3):649-655

49. Kahraman C, Öztayşi B, Sarı İU, Turanoğlu E (2014) Fuzzy analytic hierarchy process with interval type-2 fuzzy sets. Knowl-Based Syst 59:48-57

50. Abdullah L, Najib L (2014) A new type-2 fuzzy set of linguistic variables for the fuzzy analytic hierarchy process. Expert Syst Appl 41(7):3297-3305

51. Sadiq R, Tesfamariam S (2009) Environmental decision-making under uncertainty using intuitionistic fuzzy analytic hierarchy process (IF-AHP). Stoch Env Res Risk Assess 23(1):75-91

52. Abdullah L, Sunadia J, Imran T (2009) A new analytic hierarchy process in multi-attribute group decision making. Int J Soft Comput 4(5):208-214

53. Wang H, Qian G, Feng X (2011) An intuitionistic fuzzy AHP based on synthesis of eigenvectors and its application. Inform Technol J 10(10):1850-1866

54. Zhang, C., Li, W., \& Wang, L. (2011, July). AHP under the intuitionistic fuzzy environment. In 2011 Eighth International Conference on Fuzzy Systems and Knowledge Discovery (FSKD) (Vol. 1, pp. 583-587). IEEE.

55. Wu J, Huang HB, Cao QW (2013) Research on AHP with intervalvalued intuitionistic fuzzy sets and its application in multi-criteria decision making problems. Appl Math Model 37(24):9898-9906

56. Kaur P (2014) Selection of vendor based on intuitionistic fuzzy analytical hierarchy process. Adv Oper Res. https://doi. org/10.1155/2014/987690

57. Xu Z, Liao H (2013) Intuitionistic fuzzy analytic hierarchy process. IEEE Trans Fuzzy Syst 22(4):749-761

58. Abdullah L, Najib L (2016) Sustainable energy planning decision using the intuitionistic fuzzy analytic hierarchy process: choosing energy technology in Malaysia. Int J Sustain Energ 35(4):360-377

59. Dutta B, Guha D (2015) Preference programming approach for solving intuitionistic fuzzy AHP. Int J Comput Intell Syst 8(5):977-991

60. Keshavarzfard R, Makui A (2015) An IF-DEMATEL-AHP based on triangular intuitionistic fuzzy numbers (TIFNs). Decis Sci Lett 4(2):237-246

61. Onar SC, Oztaysi B, Otay İ, Kahraman C (2015) Multi-expert wind energy technology selection using interval-valued intuitionistic fuzzy sets. Energy 90:274-285

62. Öztaysi B, Onar SÇ, Boltürk E, Kahraman C (2015) Hesitant fuzzy analytic hierarchy process. In: 2015 IEEE international conference on fuzzy systems (FUZZ-IEEE). IEEE, pp. 1-7

63. Tüysüz F, Şimşek B (2017) A hesitant fuzzy linguistic term sets-based AHP approach for analyzing the performance evaluation factors: an application to cargo sector. Complex Intell Syst 3(3):167-175

64. Kahraman C, Onar SÇ, Öztayşi B (2018) B2C marketplace prioritization using hesitant fuzzy linguistic AHP. Int J Fuzzy Syst 20(7):2202-2215

65. Azadeh A, Saberi M, Atashbar NZ, Chang E, Pazhoheshfar P (2013) Z-AHP: a Z-number extension of fuzzy analytical hierarchy process. In: 2013 7th IEEE International Conference on Digital Ecosystems and Technologies (DEST). IEEE, pp 141-147

66. Zhang SS (2017) A model of based on Z-number and fuzzy analytic hierarchy process. J Math Inform 7:63-71

67. Kahraman C, Oztaysi B, Onar SC (2019) Performance Comparisons of Law Offices and Optimum Allocation of Debt Files Using Z-Fuzzy AHP. In: 2019 Conference of the International Fuzzy Systems Association and the European Society for Fuzzy Logic and Technology (EUSFLAT 2019). Atlantis Press 
68. Kahraman C, Otay I (2018) Solar PV power plant location selection using a Z-fuzzy number based AHP. Int J Anal Hierarchy Process 10(3):409-430

69. Ilbahar E, Karaşan A, Cebi S, Kahraman C (2018) A novel approach to risk assessment for occupational health and safety using Pythagorean fuzzy AHP \& fuzzy inference system. Saf Sci 103:124-136

70. Gündoğdu FK, Kahraman C (2020) A novel spherical fuzzy analytic hierarchy process and its renewable energy application. Soft Comput 24(6):4607-4621

71. Zavadskas EK, Turskis Z, Antucheviciene J, Zakarevicius A (2012) Optimization of weighted aggregated sum product assessment. Elektronika ir Elektrotechnika 122(6):3-6

72. Zavadskas EK, Antucheviciene J, Hajiagha SHR, Hashemi SS (2014) Extension of weighted aggregated sum product assessment with interval-valued intuitionistic fuzzy numbers (WASPASIVIF). Appl Soft Comput 24:1013-1021

73. Mardani A, Nilashi M, Zakuan N, Loganathan N, Soheilirad S, Saman MZM, Ibrahim O (2017) A systematic review and meta-Analysis of SWARA and WASPAS methods: theory and applications with recent fuzzy developments. Appl Soft Comput 57:265-292

74. Ilbahar E, Kahraman C (2018) Retail store performance measurement using a novel interval-valued Pythagorean fuzzy WASPAS method. J Intell Fuzzy Syst 35(3):3835-3846

75. Can GF (2018) An intutionistic approach based on failure mode and effect analysis for prioritizing corrective and preventive strategies. Human Factors Ergon Manuf Serv Ind 28(3):130-147

76. Turskis Z, Zavadskas EK, Antucheviciene J, Kosareva N (2015) A hybrid model based on fuzzy AHP and fuzzy WASPAS for construction site selection. Int J Comput Commun Control 10(6):113-128

77. Ghorabaee MK, Zavadskas EK, Amiri M, Esmaeili A (2016) Multi-criteria evaluation of green suppliers using an extended WASPAS method with interval type-2 fuzzy sets. J Clean Prod 137:213-229

78. Keshavarz Ghorabaee M, Amiri M, Kazimieras Zavadskas E, Antuchevičiené J (2017) Assessment of third-party logistics providers using a CRITIC-WASPAS approach with interval type-2 fuzzy sets. Transport 32(1):66-78

79. Peng X, Dai J (2017) Hesitant fuzzy soft decision making methods based on WASPAS, MABAC and COPRAS with combined weights. J Intell Fuzzy Syst 33(2):1313-1325

80. Ren R, Liao H, Al-Barakati A, Cavallaro F (2019) Electric vehicle charging station site selection by an integrated hesitant fuzzy SWARA-WASPAS method. Transform Bus Econ 18(2):103-123

81. Mishra AR, Rani P, Pardasani KR, Mardani A (2019) A novel hesitant fuzzy WASPAS method for assessment of green supplier problem based on exponential information measures. J Clean Prod 238:117901

82. Nie RX, Wang JQ, Zhang HY (2017) Solving solar-wind power station location problem using an extended weighted aggregated sum product assessment (WASPAS) technique with interval neutrosophic sets. Symmetry 9(7):106

83. Kahraman C, Onar SÇ, Oztaysi B, Ilbahar E (2019) Selection among GSM operators using Pythagorean fuzzy WASPAS Method. J Mult Value Logic Soft Comput 33:459-469
84. Kutlu Gundogdu F, Kahraman C (2019) Extension of WASPAS with spherical fuzzy sets. Informatica 30(2):269-292

85. Turskis Z, Goranin N, Nurusheva A, Boranbayev S (2019) A fuzzy WASPAS-based approach to determine critical information infrastructures of EU sustainable development. Sustainability 11(2):424

86. Chandrawati TB, Ratna AAP, Sari RF (2020) Path selection using fuzzy weight aggregated sum product assessment. Int J Comput Commun Control 15(5):3978

87. Saraswat SK, Digalwar A, Yadav SS (2020) Development of assessment model for selection of sustainable energy source in India: hybrid fuzzy MCDM approach. In: International Conference on Intelligent and Fuzzy Systems. Springer, Cham, pp 649-657

88. Ayyildiz E, Gumus AT (2020) A novel spherical fuzzy AHP-integrated spherical WASPAS methodology for petrol station location selection problem: a real case study for İstanbul. Environ Sci Pollut Res 27(29):36109-36120

89. Otay I, Atik S (2020). Multi-criteria oil station location evaluation using spherical AHP\&WASPAS: a real-life case study. In: International Conference on Intelligent and Fuzzy Systems. Springer, Cham, pp 591-598

90. Otay I, Kahraman C, Öztayşi B, Onar SÇ (2020) A novel singlevalued spherical fuzzy AHP-WASPAS methodology. Fuzzy Logic Intell Technol Nuclear Sci 190-198

91. Zadeh LA (2011) A note on Z-numbers. Inf Sci 181(14):2923-2932

92. Abiyev RH, Uyar K, Ilhan U, Imanov E, Abiyeva E (2018) Estimation of food security risk level using Z-number-based fuzzy system. J Food Qual 2018:9 (Article ID 2760907)

93. Yildiz N, Kahraman C (2019) Evaluation of social sustainable development factors using Buckley's fuzzy AHP based on Z-numbers. In: International Conference on Intelligent and Fuzzy Systems. Springer, Cham, pp 770-778

94. Yildiz N, Kahraman C (2020) CODAS method using Z-fuzzy numbers. J Intell Fuzzy Syst 1-14, (Preprint)

95. Bozanic D, Tešić D, Milić A (2020) Multicriteria decision making model with Z-numbers based on FUCOM and MABAC model. Decis Mak Appl Manag Eng 3(2):19-36

96. Bahadori M, Teymourzadeh E, Ravangard R, Raadabadi M (2017) Factors affecting the overcrowding in outpatient healthcare. J Educ Health Promot 6(1):21

97. Guerrero LA, Maas G, Hogland W (2013) Solid waste management challenges for cities in developing countries. Waste Manag 33(1):220-232

98. Chakraborty S, Zavadskas EK, Antucheviciene J (2015) Applications of WASPAS method as a multi-criteria decision-making tool. Econ Comput Econ Cybern Stud Res 49(1):5-22

Publisher's Note Springer Nature remains neutral with regard to jurisdictional claims in published maps and institutional affiliations. 